\title{
Correction to: A performance measure approach for risk optimization
}

\author{
André Jacomel Torii ${ }^{1} \cdot$ Rafael Holdorf Lopez ${ }^{2} \cdot$ André Téofilo Beck $^{3} \cdot$ Leandro Fleck Fadel Miguel $^{2}$
}

Received: 10 April 2019 / Accepted: 15 April 2019 / Published online: 17 May 2019

(C) Springer-Verlag GmbH Germany, part of Springer Nature 2019

\section{Correction to: Structural and Multidisciplinary Optimization https://doi.org/10.1007/s00158-019-02243-5}

The original article unfortunately contains error in one of the equations and the results of the last example. This is also to emphasize that these corrections do not affect the conclusions of the paper.

Responsible Editor: Raphael Haftka

The online version of the original article can be found at https://doi.org/10.1007/s00158-019-02243-5.

André Jacomel Torii

ajtorii@hotmail.com

1 Latin American Institute of Technology, Infrastructure and Territory (ILATIT), Federal University of Latin American Integration (UNILA), Av. Tancredo Neves 6731, Foz do Iguaçu, PR, 85867-970 Brazil

2 Center for Optimization and Reliability in Engineering (CORE), Department of Civil Engineering, Federal University of Santa Catarina (UFSC), Rua João Pio Duarte, s/n, Florianópolis, SC, 88040-900 Brazil

3 Structural Engineering Department, University of São Paulo, Av. Trabalhador São-Carlense, 400, São Carlos SP, 13566-590 Brazil
Equation (46) in Section 5.4, concerning the cantilever beam, should be corrected to

$C=\frac{1}{3} h b^{2} G$.

The numerical results are correct, since this was just a typing error.

In Section 5.5, concerning the reinforced concrete arch, the computational routines for evaluation of the volume of the structure were incorrect. Thus, the correct optimal designs are slightly different, even though the conclusions remain the same. The correct deterministic design is

$\mathbf{d}=\{66.99,0.28,0.66,1.35,1.44,0.94,1.63,3.21\}$.

The correct risk optimization design is

$\mathbf{d}=\{81.91,0.35,0.72,1.35,1.44,0.92,1.61,3.21\}$.

The critical buckling load factor and the critical resistance factor are $\lambda_{c r}=1.7954$ and $r_{c r}=\mu / \mu_{r}=0.5673$, respectively. Equation (59) should be corrected to

$\mathbf{d}^{(0)}=\kappa \times\{81.91,0.35,0.72,1.35,1.44,0.92,1.61,3.21\}$.

Figures 8, 9, 10 and 11 should be corrected to Figs. 8-11 presented below. Tables 15, 16 and 17 should be corrected to Tables 15-17 presented below. 
Fig. 8 Example 5: Deterministic design

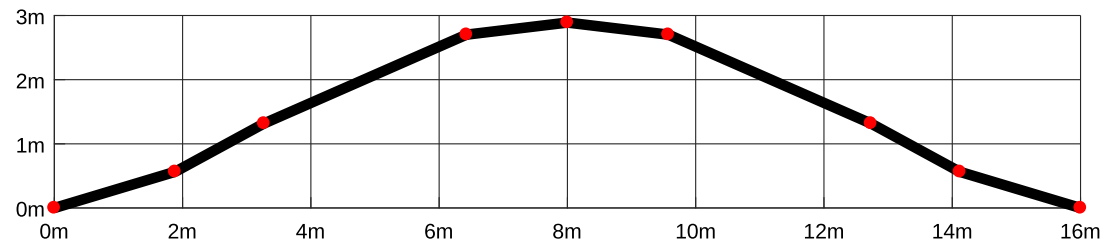

Fig. 9 Example 5: Risk

Optimization design
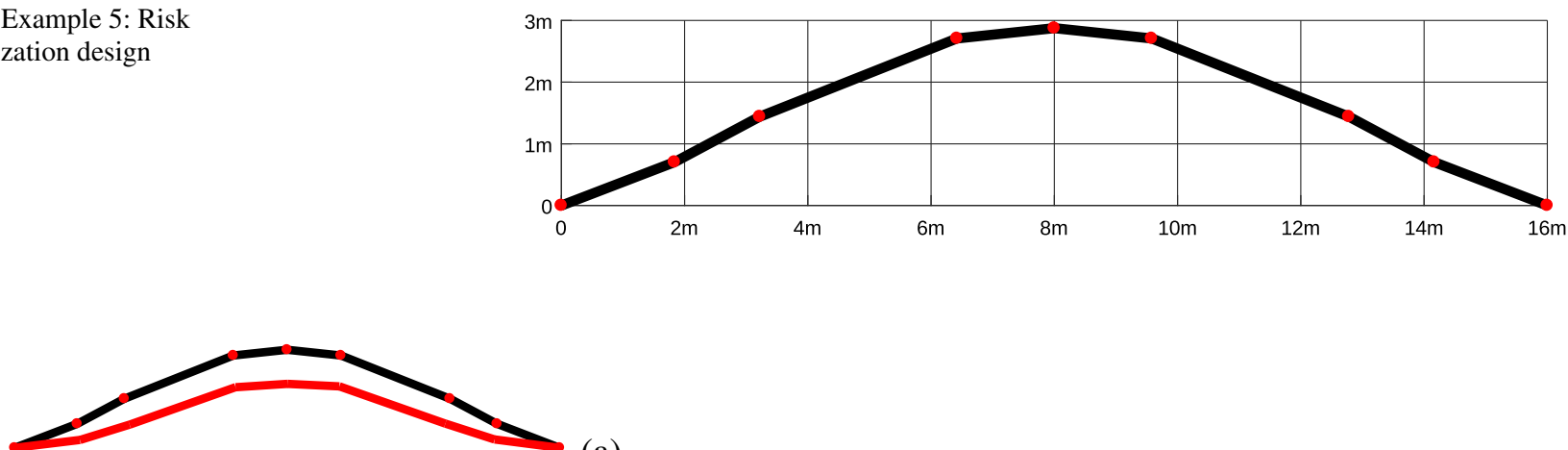

(a)

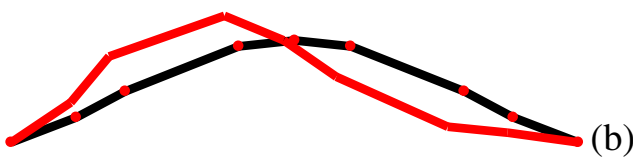

Fig. 10 Example 5: a displacements and $\mathbf{b}$ critical buckling mode of the optimum design

Fig. 11 Example 5: evolution of the total cost obtained with PMA-SORA

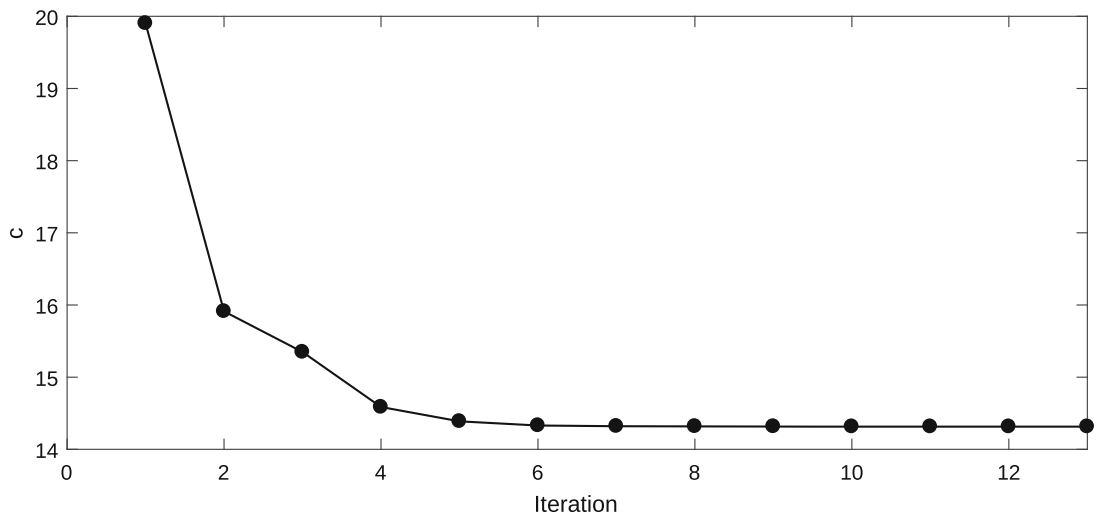

Table 15 Example 5: comparison of the results

\begin{tabular}{|c|c|c|c|c|}
\hline Approaches & Initial solution & $c$ & $\mathrm{NFE}^{*}$ & $\beta$ \\
\hline PMA-SORA & Parabolic & 14.3483 & $2,780(52,820)$ & $\{3.0121,3.4879\}$ \\
\hline PMA-SORA & Deterministic & 14.3483 & $2,759(52,421)$ & $\{3.0156,3.4597\}$ \\
\hline RO-IP & Parabolic & \multicolumn{3}{|c|}{ Fails to converge at the first iteration } \\
\hline RO-IP & Deterministic & \multicolumn{3}{|c|}{ Fails to converge at the first iteration } \\
\hline RO-HLRF & Parabolic & \multicolumn{3}{|c|}{ Fails to converge at the first iteration } \\
\hline RO-HLRF & Deterministic & \multicolumn{3}{|c|}{ Fails to converge at the first iteration } \\
\hline
\end{tabular}

*NFE in parenthesis consider gradient evaluation with forward finite differences 
Table 16 Example 5: results obtained with PMA-SORA

\begin{tabular}{llll}
\hline Iteration & $c$ & $\mathbf{d}$ & $\beta$ \\
\hline 1 & 19.9035 & $\{76.33,0.31,0.69,1.35,1.44,0.93,1.62,3.21\}$ & $\{2.00,2.00\}$ \\
2 & 15.9118 & $\{78.81,0.31,0.68,1.35,1.43,0.93,1.62,3.21\}$ & $\{2.50,2.26\}$ \\
3 & 15.3487 & $\{78.59,0.34,0.71,1.35,1.44,0.92,1.61,3.21\}$ & $\{2.41,2.77\}$ \\
4 & 14.5862 & $\{80.08,0.34,0.71,1.35,1.44,0.92,1.61,3.21\}$ & $\{2.70,2.91\}$ \\
5 & 14.3882 & $\{80.98,0.34,0.71,1.35,1.44,0.92,1.61,3.21\}$ & $\{2.87,3.07\}$ \\
6 & 14.3306 & $\{81.62,0.34,0.71,1.35,1.44,0.92,1.61,3.21\}$ & $\{2.98,3.21\}$ \\
7 & 14.3208 & $\{81.90,0.35,0.71,1.35,1.44,0.92,1.61,3.21\}$ & $\{3.03,3.30\}$ \\
8 & 14.3184 & $\{82.00,0.35,0.72,1.35,1.44,0.92,1.61,3.21\}$ & $\{3.04,3.35\}$ \\
9 & 14.3167 & $\{82.02,0.35,0.72,1.35,1.44,0.92,1.61,3.21\}$ & $\{3.04,3.40\}$ \\
10 & 14.3154 & $\{81.99,0.35,0.72,1.35,1.44,0.92,1.61,3.21\}$ & $\{3.03,3.45\}$ \\
11 & 14.3151 & $\{81.93,0.35,0.72,1.35,1.44,0.92,1.61,3.21\}$ & $\{3.02,3.46\}$ \\
12 & 14.3151 & $\{81.91,0.35,0.72,1.35,1.44,0.92,1.61,3.21\}$ & $\{3.02,3.46\}$ \\
13 & 14.3151 & $\{81.91,0.35,0.72,1.35,1.44,0.92,1.61,3.21\}$ & $\{3.02,3.46\}$ \\
\hline
\end{tabular}

Table 17 Example 5: NFE* for different values of $\kappa$

\begin{tabular}{lll}
\hline Approaches & $\kappa=0.9$ & $\kappa=1.1$ \\
\hline PMA-SORA & $2,621(49,799)$ & $2,583(49,077)$ \\
RO-IP & failed & $1,782(36,100)$ \\
RO-HLRF & failed & $867(18,981)$ \\
\hline
\end{tabular}

*NFE in parenthesis consider gradient evaluation with forward finite differences

Publisher's note Springer Nature remains neutral with regard to jurisdictional claims in published maps and institutional affiliations. 